\section{Levante en la obra sinfónica del maestro Óscar Esplá1}

\section{Levant in Óscar Esplá's symphonic work}

\author{
Rosa Elia Castelló Gómara \\ Universidad de Alicante, \\ España \\ rosaelia@ono.com \\ https://orcid.org/0000-0002-7817-0646
}

Cómo citar este artículo:

CASTELLÓ GÓMARA; R. E. (2020). "Levante en la obra sinfónica del maestro Óscar Esplá", Pangeas. Revista Interdisciplinar de Ecocrítica, 2, pp. 61-73. https://doi.org/10.14198/pangeas2020.2.05

\section{RESUMEN}

El compositor alicantino Oscar Esplá (18861976) ocupa junto a Falla, Julio Gómez y Conrado del Campo un lugar preeminente en la historia de la música española del siglo XX, y no sólo por su extenso catálogo de partituras y escritos sobre música, sino también por haber participado activa-mente en el proceso de regeneración musical (que venía gestándose desde fines del siglo XIX gracias a los trabajos de Barbieri y Pedrell) llevada a cabo por toda una generación de compositores concien-ciados de la imperiosa necesidad de situar la música española al nivel europeo; para ello el primer paso debía

\footnotetext{
${ }^{1}$ El artículo "Levante en la obra sinfónica del maestro Óscar Esplá" tiene como fuente bibliográfica principal la tesis de doctorado de Rosa Elia Castelló Gómara La obra de Oscar Esplá: Música, literatura y pensamiento estético, dirigida por los doctores Pedro Aullón de Haro y José María Esteve Faubel, y leída en la Universidad de Alicante el 15 de abril de 2013.
}

ser concienciar a los composi-tores de la necesidad de cuidar su formación intelectual y cultural preocupándose no sólo de la técnica compositiva sino profundizando en cues-tiones estéticas y musicológicas, para abordar el hecho musical desde todos sus ámbitos dado que es la única forma de obtener una idea completa, global y real de la obra de arte musical.

Sus obras, siempre revestidas de un deseo de perfección y especialmente la Sinfonía Aitana, son el legado de un compositor con conciencia mediterránea. Esplá no es un nacionalista en el sentido estricto de la palabra ya que su honda sensibilidad mediterránea aflora de forma espontánea en unas obras que no suelen utilizar citas folklóricas textuales. Con un estilo personalísimo, al igual que lo hiciera Turina o Falla con lo andaluz, la música de Esplá se convierte en la voz de la región levantina, en el sonido de las tierras bañadas por el Mediterráneo, con toda su luz y sensibilidad.

Palabras clave: Óscar Esplá; Levante; Aitana; música; sinfonía programática; poema sinfónico

\begin{abstract}
The composer Oscar Esplá from Alicante (18861976), together with Falla, Julio Gómez and Conrado del Campo, occupies a pre-eminent place in the history of twentieth-century Spanish music, and not only because of his extensive catalog of music scores and writings, but also also for having actively participated in the process of musical regeneration
\end{abstract}




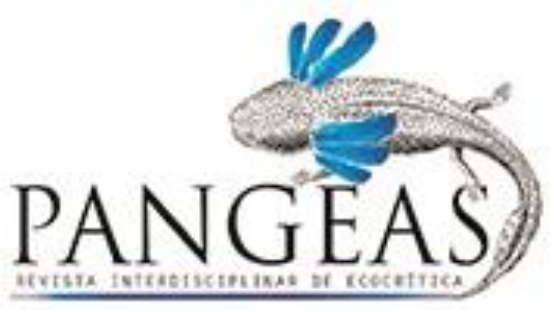

(which had been developing since the late nineteenth century thanks to the works of Barbieri and Pedrell) carried out by a whole generation of composers aware of the urgent need to place Spanish music at the same level European; for this, the first step should be to make composers aware of the need to take care of their intellectual and cultural education, not only focusing on the compositional technique, but also on aesthetic and musicological questions, in order to approach the musical fact from all its areas, as it is the only one way to get a complete, global and real idea of the musical art work.

His works, always covered with a desire for perfection and especially the Aitana Symphony, are the legacy of a composer with a Mediterranean conscience. Esplá is not a nationalist in the strict sense of the word since his deep Mediterranean sensibility surfaces spontaneously in works that do not usually use textual folkloric quotes. With a personal style, like Turina or Falla with the Andalusian, the music of Esplá becomes the voice of the Levantine region, in the sound of the lands

Imagen 1: "Oscar Esplá". Óleo restaurado de Manuel Baeza. Conservado en Biblioteca Gabriel Miró.

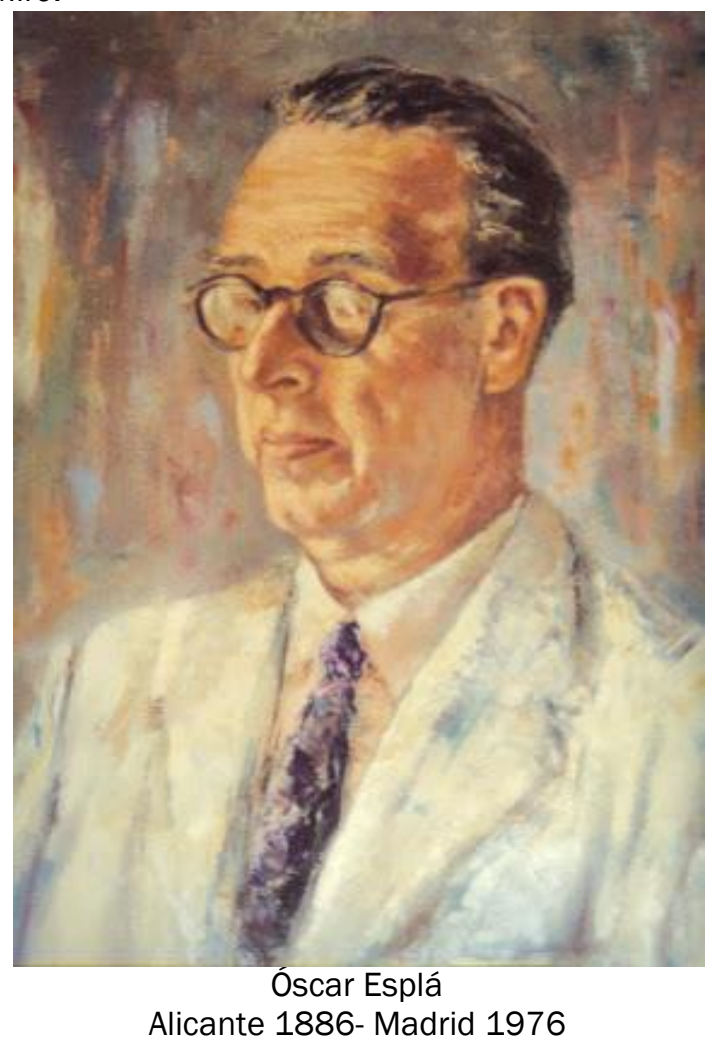
bathed by the Mediterranean, with all its light and sensibility.

Keywords: Óscar Esplá; Levante; Aitana; music; programmatical symphony; tone poem. 


\section{Introducción}

La naturaleza y los animales han sido una fuente inagotable de inspiración para los compositores de todas las épocas, ya sea vertiendo en los pentagramas las sensaciones y pensamientos suscitados a partir de la contemplación de los paisajes, intentado describir la Naturaleza contemplada o bien reproduciendo los fenómenos acústicos escuchados que, por efecto sinestésico, nos evocan sus paisajes. Baste como ejemplo, las conocidísimas Cuatro Estaciones de Vivaldi, la Sinfonía n. o 6 "Pastoral" de Beethoven, El carnaval de los animales de Saint-Saens, El Moldava de Smetana, Pedro y el Lobo de Prokofiev o La mer de Debussy.

La intención de utilizar la música con propósitos descriptivos se pierde en la noche de los tiempos; así mismo, la cuestión de si la música por sí sola es capaz de describir algo también es antigua y nunca ha recibido una respuesta definitiva, dado el carácter no representativo y evidentemente subjetivo propio de la música. Por ello, es cuestionable si los oyentes reconocen lo que se está describiendo con la música sin la ayuda de títulos, sinopsis, notas de programa, citas literales o citas de melodías conocidas.

En el siglo XX, emerge de forma destacada la figura del alicantino Óscar Esplá (compositor, pianista y pensador) cuya compleja obra compositiva está caracterizada por dos elementos fundamentales: 1) la defensa, por encima de toda moda y crítica, de las posibilidades del sistema tonal y 2) Levante como fuente omnipresente, constante y recurrente de inspiración. Impresiones musicales, Evocaciones, La sierra, La pájara pinta, Canciones Playeras, Sinfonía Aitana, Sonata del Sur.... suenan a Levante, a Mediterráneo, a Aitana.

\section{Sinfonía Aitana}

Aitana y todo lo que la rodea (flora, fauna...) inspirará y dará título a la obra más emblemática de Óscar Esplá, Sinfonía Aitana, subtitulada "A la música tonal in memoriam". Partitura en la que están presentes, como es habitual en Esplá, sus cualidades nacionales, o más bien regionales y levantinas, sin menoscabo de un europeísmo y una categoría universal. En esta obra confluyen la gran forma, la sensibilidad mediterránea en expresión estilizada de localismo y la orquestación magistral. El sinfonismo de Esplá es nuevo, basado en esencias nacionales incorporadas al momento contemporáneo de su arte evolucionado, en signo de positivo avance. El maestro alicantino pone su sabiduría al servicio de ideaciones, resultando tanto más trascendente cuanto mayor y más alto es su propósito.

Compuesta en el año $1957^{2}$, la Sinfonía Aitana Op. 56 fue escuchada por vez primera interpretada por la Orquesta Municipal de Alicante dirigida por el maestro Odón Alonso en un concierto celebrado en el Teatro Principal de Alicante para clausurar el curso de la Sociedad Filarmónica. Sin embargo, el verdadero estreno mundial de la obra tendría lugar seis años después, concretamente el sábado 31 de octubre de 1964 en el Teatro del Ministerio de Información y Turismo de la capital de España, dentro de los actos que conmemoraban la clausura al I Festival de Música de América y España organizado por el Instituto de Cultura Hispánica, con la colaboración del Ministerio de Información y la Organización de Estados Americanos. Junto a la Sinfonía de Esplá en el programa figuraban una Sinfonía del panameño Roque Cordero, las Secuencias de Cristóbal Halffter en una nueva versión revisada y, por último, el también estreno de la Sinfonía de Don Rodrigo de Alberto Ginastera; todo ello interpretado por la Orquesta Nacional de España dirigida por el maestro Rafael Frühbeck de Burgos. El estreno de la

\footnotetext{
${ }^{2}$ Ponemos la fecha de 1957 por ser la que aparece en la partitura autógrafa conservada en el Fondo Documental Óscar Esplá.
} 
partitura de Esplá coincidió con la imposición a Esplá por el entonces ministro de Información y Turismo Manuel Fraga Iribarne de la Gran Cruz de la Orden de Alfonso X, el Sabio 3 .

Imagen 2: Partitura manuscrita de la Sinfonía Aitana, en el Fondo Documental Óscar Esplá.

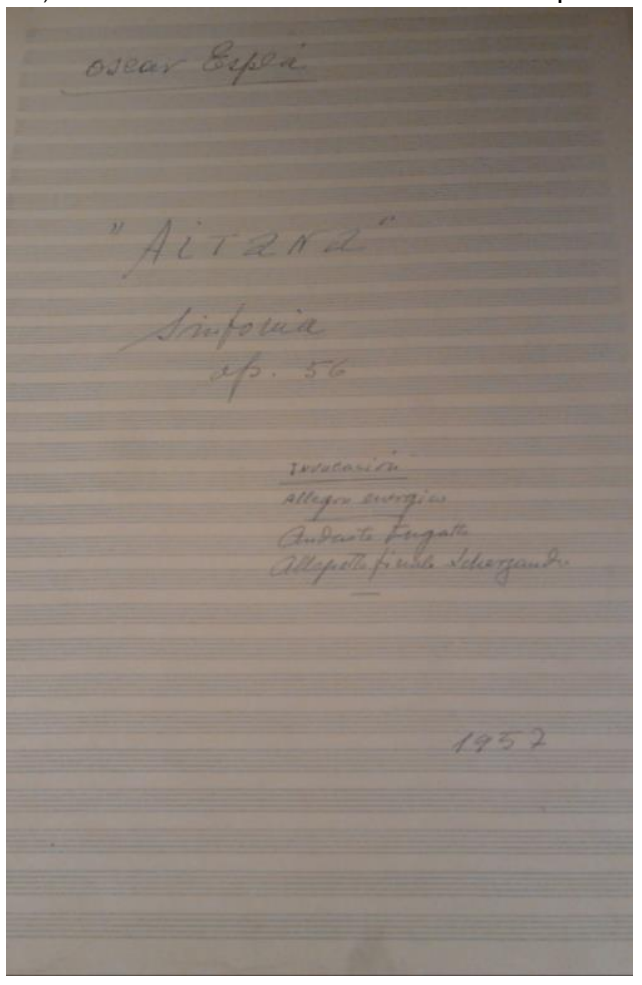

A pesar de titularse "Sinfonía" quizá estemos ante un poema sinfónico o una sinfonía programática, puesto que el planteamiento de la partitura de Esplá se acerca más a este tipo de composiciones. El poema sinfónico es un producto típico del romanticismo musical; nació de esa concepción romántica de la unidad de las artes, según la cual las distintas manifestaciones artísticas se consideran estrechamente vinculadas entre sí, surgidas de una única matriz, y no ya como fenómenos autónomos, según había ocurrido con la estética clásica (Plantinga, 1984; Benedetto, 1987). A tenor de dicha

\footnotetext{
${ }^{3}$ Fondo Documental Óscar Esplá de la Biblioteca Gabriel Miró de Alicante.
}

concepción, una composición musical puede inspirarse legíti-mamente en un trabajo literario, en un paisaje pictórico, en una visión filosófica, un sentimiento, una sensación, etc. Mientras en la sinfonía el tema musical se presenta como algo |64 susceptible de desarrollo a lo largo de la pieza, como una semilla de la que brotará poco a poco la planta, en el poema sinfónico existen motivos ya completos, que no desarrollan sino que se transforman siguiendo el curso de las ideas extramusicales que los apoyan y de las que ellos constituyen la metáfora sonora. Si la fuerza que genera la sinfonía es el desarrollo temático; la del poema sinfónico es la metamorfosis de los motivos. En efecto, con las variaciones se logra la finalidad de traducir, mediante la unidad del tema y la multiplicidad de sus transformaciones, la identidad del motivo poético inspirador y la diversidad de las formas que el mismo motivo asume en su desarrollo.

El primero que compuso poemas sinfónicos y les dió esta denominación fue Franz Liszt, que escribió trece trabajos de este género que van desde una temática inspiradora concreta hacia otra más abstracta: Por ejemplo, La batalla de los hunos está inspirada en el homónimo cuadro del pintor Kaulbach, donde un obispo empuñando la cruz, se eleva por encima de la multitud en lucha, eficazmente descrita por la música, y convierte al cristianismo a los guerreros paganos; en Tasso y Mazeppa (basada en una obra de Víctor Hugo) se evocan dos destinos personales y se trazan escenas reales, de baile en el primero y de cabalgata en el segundo; en Gamlet $y$ Prometeo prescinden de la descripción de los caracteres para dar una mejor idea del ánimo humano y del mito; Hungría tiene por tema el destino de las naciones. Los preludios e Ideales cantan las aspiraciones y los valores universales del hombre; el título del primero se inspira en las palabras de Lamartine: “¿No 
es acaso nuestra vida una serie de preludios para/ ese canto misterioso/ del que la muerte eleva la primera y solemne nota?" (s. p.). Lo que se siente en la montaña (sobre otra obra de Víctor Hugo) ensalza la lucha del hombre con la naturaleza. Y finalmente, Ecos de fiesta y Orfeo celebran el poder mágico de la música.

El sucesor inmediato en el ámbito del poema sinfónico fue el compositor francés Camille Saint-Saëns ${ }^{4}$, cuya obra más conocida en dicho género fue la Danza macabra. Y en la misma época que Saint-Saëns, el bohemio Bedrich Smetana adoptaba el principio del poema sinfónico en el ciclo de sus seis trabajos reunidos bajo el título de $\mathrm{Mi}$ patria, entre los que destaca El Moldava, donde varios episodios describen los distintos aspectos asumidos durante su curso por este río, desde las dos pequeñas fuentes de las que nace hasta su confluencia con el Danubio, pasando por los bosques animados por la caza, las praderas alegradas por los cantos y bailes campesinos y la ciudad de Praga, con sus cien torres.

Mili Balakirev, Alexandr Borodin, Nicolai Rismsky-Korsakov, Modest Mussorgski, Piotr Ilich Tcahikovski, Alexandre Scriabin, César Frank, Vincent D`Indy, Paul Dukas, Arthur Honegger, Alexandr Mossolov, Claude Debussy, Ottorino Respighi... entre otros, compusieron obras que encajan dentro de la forma poema sinfónico; sin embargo, el género alcanzó su apogeo con los siete poemas sinfónicos de Richard Strauss. El primero de ellos, Don Juan, se inspira en un poema de Lenau, que contempla al universal personaje "libertino" como un héroe cuyo deseo queda siempre insaciado, y que termina víctima no ya del infierno, sino del desencanto. Así hablaba Zaratustra, inspirado en el texto homónimo del filósofo Friedrich Nietzsche donde el antiguo profeta

\footnotetext{
${ }^{4}$ Recordemos que Camille Saint-Saëns fue profesor de Oscar Esplá.
}

Zarathustra o Zoroastro pronuncia una serie de predicciones con respecto a la humanidad. El tema con variaciones y epílogo Don Quijote se basa en la novela de Miguel de Cervantes. La grandiosidad de Vida de héroe describe un héroe imaginario, invento de Strauss, el cual tomó las características, los personajes secundarios y las aventuras de su propia vida. Las travesuras de Till Eulenspiegel (nombre de un personaje legendario alemán del siglo XIV) cuenta la vida de un bribón alemán que termina en la horca por haberse burlado de los poderosos, es la obra cumbre de la serie de poemas sinfónicos de Strauss.

Junto a los poemas sinfónicos propiamente dichos, Strauss compuso también sinfonías programáticas ${ }^{5}$ como la autobiográfica Sinfonía doméstica o la Sinfonía alpina, escrita en el año 1915 (obra que conecta con la Sinfonía Aitana de Oscar Esplá) y en la que el compositor alemán amplía considerable-mente la orquesta consiguiendo una orquestación exuberante de enormes propor-ciones. El último de los poemas tonales de Strauss, la Sinfonía Alpina, se basa total-mente en una descripción naturalística, describiendo un imaginario ascenso y descenso de una de las crestas de los Alpes austríacos.

Se puede establecer un paralelismo perfecto entre la Sinfonía Aitana de Esplá y la Sinfonía Alpina de Strauss, ya que ambos, al margen de la diferente ubicación y proyección argumental, plasman en los pentagramas los sentimientos y la emoción

\footnotetext{
${ }^{5}$ La sinfonía programática nace al mismo tiempo que el poema sinfónico, en el pleno siglo XIX respondiendo a ese gusto por la utilización de elementos extramusicales, especialmente poéticos, que tienen los compositores de esta época. Estructuralmente, la diferencia esencial entre un poema sinfónico y una sinfonía programática es que en el primero no hay seccionalización en movimientos indepen-dientes (aunque éstos existan) mientras que en la sinfonía programática se mantiene la típica subdivisión en cuatro movimientos que tenían las sinfonías desde el clasicismo, pero ahora dotadas de un contenido extramusical (literario, pictórico, sentimental, histórico...).
} 
que les embarga al contemplar esos paisajes que forman parte de su personalidad más íntima y profunda. Así mismo, escuchando el primer tiempo de la Aitana de Esplá nos envuelve una situación espiritual semejante a la que transmite la Pastoral de Beethoven: Esplá expone situaciones líricas vividas en aquella sierra (la Aitana alicantina), al igual que el compositor de Bonn y Strauss ponen en música sus sentimientos ante la contemplación de los campos de su región. No hay descriptivismos, ni citas popularistas, sino la personal emoción de un hombre ante un paisaje como fórmula que resumiera una relación hombre-naturaleza. Es el arte como canto personal encarnado en una técnica consumada. Por los pentagramas de la Aitana no discurren narraciones, pero se transmite la experiencia estética de un hombre en medio de un paisaje y rodeado por una fauna que se refugia en la soledad y tranquilidad de estos parajes agrestes. Esplá, nuevo Sigüenza, nos lleva por los caminos de la Aitana, caminos de años y leguas. Si ya en la Nochebuena del diablo, en cierto modo, nos encontramos los paisajes y el clima de la bella sierra alicantina, ahora los hemos vuelto a encontrar con toda su plenitud de sugerencias emotivas y con todo un mundo de sugestiones en los que se recrean las notas de Esplá.

Imagen 3. Guadalest / Sierra de Aitana / Gabriel Miró, Años y Leguas
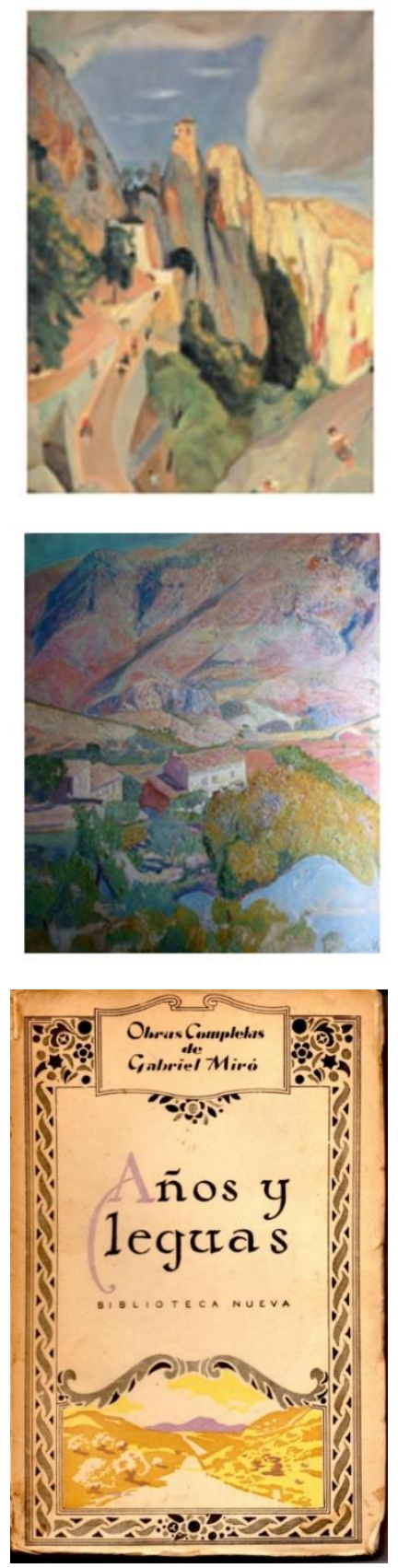

A pesar de que el compositor dice no haber recurrido a exactas alusiones folklóricas, las melodías y su consiguiente invitación armónica recuerdan sin duda alguna a los cantos populares de las dulzainas de La Nucía, Polop o Guadalest. Y aquí reside su mérito, el de su inventiva y su sensibilidad. El paisaje soñado de Aitana no se pierde en ningún momento incluso cuando los alardes técnicos podrían alejar del 
descriptivismo (como es el caso de la exposición de fuga del tercer movimiento).

El irónico subtítulo "A la música tonal 'in memoriam'" no debe llevarnos a error. La tonalidad no se halla ausente ni en la invención melódica ni en la armonía aún en los momentos más exasperados; siempre diáfana y limpia, elemental u ornamentada por una riqueza melódica que acepta neologismos audaces (atonales), la presencia tonal se mantiene en la base de toda la composición y pocas veces se podrá percibir su ausencia. Esplá, justificado y justificante defensor de la estética compositiva más tradicional, demostró con esta partitura que aún se podían escribir bellas páginas dentro de la tonalidad, de modo que la obra en lugar de ser un "réquiem" por la tonalidad se convierte en una glorificación de la misma.

Oscar Esplá es un compositor que no deja nada al azar, de este modo el trabajo armónico, la orquestación y la estructura formal de la Sinfonía Aitana están perfectamente pensadas. La partitura se divide en cuatro tiempos, al igual que las sinfonías clásicas: Invocación, Allegro energico, Andante fugato y Allegretto finale scherzando. Veámoslo.

\section{I. “Invocación”}

La música de este primer movimiento posee un carácter evocativo y sugerente que recuerda a las atmósferas de vaguedad, fluctuación, irrealidad e indefinición creadas por el impresionista Claude Debussy en poemas sinfónicos como El mar o Preludio a la siesta de un fauno. Incluso el título es sugerente (INVOCAR o quizá EVOCAR), como lo eran los títulos de las partituras de la mayoría de compositores impresionistas. La Sinfonía Aitana desde el mismo comienzo impresiona; la razón la encontramos no solamente en la belleza original de su melodía, sino además, porque en Esplá -al igual que en la obra de los grandes maestros-, la exposición temática se presenta con absoluta claridad, libre de todo enredo.

“Invocación" se estructura en tres grandes secciones, A (compás 1 a 86) -B (compás 87 a 112) - $A^{\prime}$ (compás 113 a 148), más una pequeña coda final (compás 149 a 154).

Imagen 4. Primeros compases del primer movimiento, “Invocación”, de la Sinfonía Aitana.
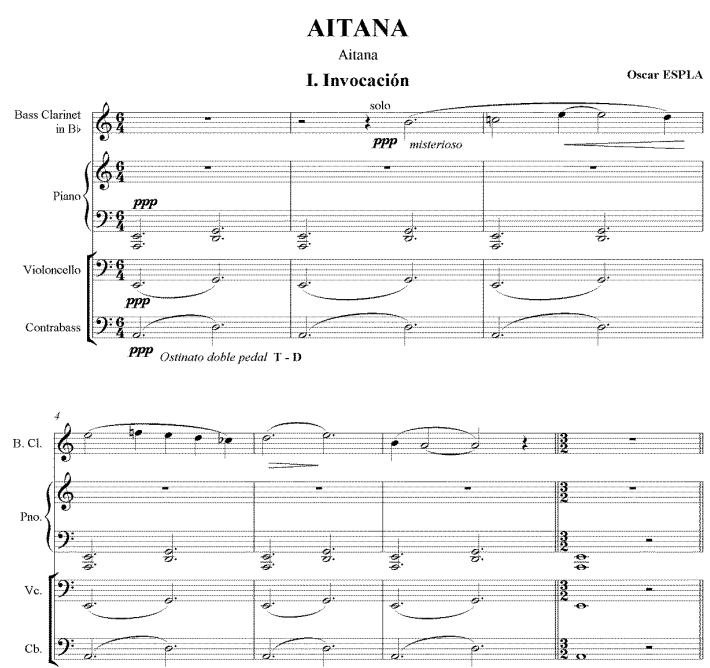

Copyright de la imagen (c) Rosa Elia Castelló Gómara

El tema principal de este primer movimiento presenta, de forma evidente, similitudes con los cantos de trilla de la zona de la Marina Alta alicantina por su carácter melancólico, por la utilización de giros de $2^{a}$ aumentadas, por el empleo de valores irregulares, el uso del oboe que recuerda a la dulzaina (instrumento habitual en el folklore levantino) y por el hecho de girar sobre el tono de la, habitual en muchas de estas piezas. Por ejemplo, El Cancionero Musical de Seguí recoge un canto de trilla de Polop de la Marina que aunque no es totalmente idéntico a la melodía de Aitana, sí se asemeja en los puntos enumerados. Además, no hemos de olvidar que Esplá hace un uso del folklore muy personal, pocas veces toma 
citas exactas; él intenta plasmar la atmósfera general y para ello utiliza elementos de esas canciones, pero adaptadas a su propia concepción.

Imagen 5. "Entre marido y mujer" canción popular de Polop de la Marina, en el Cancionero Musical de la provincia de Alicante de Salvador Seguí, publicado por Diputación Alicante.

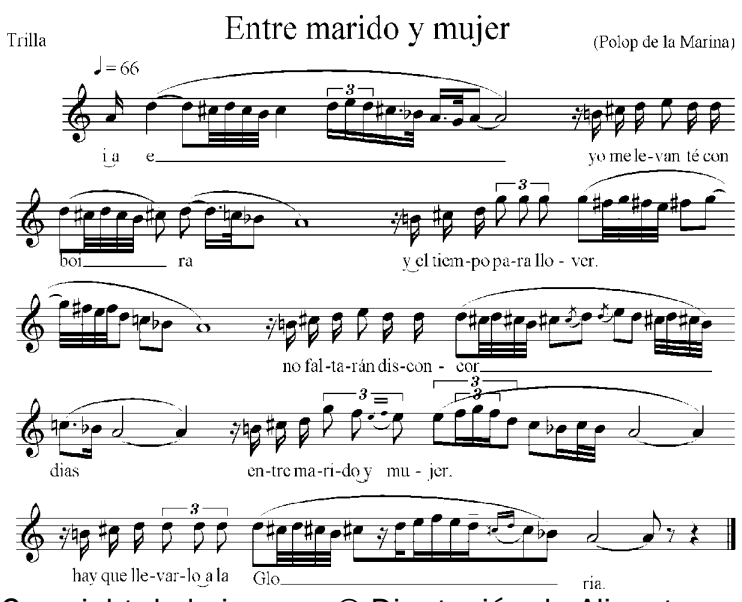

Copyright de la imagen ( Diputación de Alicante.

A menudo se ha acusado a Oscar Esplá de ser un compositor demasiado intelectual; la inspiración y la belleza que transmiten las notas de esta "Invocación" callan por sí solas cualquier crítica de exagerado intelectualismo que, por otra parte, Esplá posee y emplea, pero en su justa medida, siempre de acuerdo con su filosofía. Por lo general, toda sinfonía se divide en cuatro tiempos, el primero de los cuales suele hacer uso de una estructura de sonata (exposición, desarrollo y reexposición). Oscar Esplá en el primer tiempo de su Sinfonía Aitana parece que va a organizar el material musical siguiendo ese diseño arquitectónico que es la sonata, sin embargo no llega a hacerlo verdaderamente: ya en la primera sección (A) parece que está exponiendo dos temas, aunque en realidad al analizarlos observamos que se trata de un mismo tema modificado; la segunda sección (B) parece querer ser un desarrollo de lo expuesto en la primera (A), pero no llega a serlo, y la tercera sección $\left(A^{\prime}\right)$ vuelve al principio, pero con modificaciones puesto que los "temas" aparecen al revés. Otra de las normas de la sonata que aquí no se cumple es que los temas deben exponerse uno en la tonalidad principal y otro en la dominante, y en la reexposición los dos temas deben reaparecer en la tonalidad |68 principal; todo esto no sucede aquí, principalmente porque no llega a definirse totalmente la tonalidad en ningún momento.

Imagen 6. Esquema de la estructura musical de SONATA.

Estructura de sonata:

A) EXPOSICIÓN: presentación de temas

B) DESARROLLO: trabajo de los temas

C) REEXPOSICIÓN: reaparición de los temas musicales con las modificaciones a las que se ha llegado en el desarrollo

D) CODA (opcional): epílogo

Copyright de la imagen (c) Rosa Elia Castelló Gómara

\section{II. “Allegro energico"}

El segundo tiempo de la Sinfonía Aitana, "Allegro energico", es una especie de forma lied estructurada en tres partes principales, $A$ (compás 1 a 48) - B (compás 49 a 96) - A (compás 97 a).

La primera parte A comienza con la presentación de un pequeño motivo rítmicomelódico que será la base de toda la esta primera sección. Esplá no llega a desarrollar un verdadero tema, sino que estamos ante una célula motívica a partir de la cual va haciendo variaciones rítmicas, melódicas, armónicas y tímbricas. Al maestro alicantino le gustaba emplear esos pequeños motivos y después jugar con ellos modificándolos hasta el extremo. Este modo de componer recuerda a la técnica utilizada a menudo por Johannes Brahms llamada "variación en desarrollo" que consistía precisamente en eso, presentar un pequeño motivo del cual emergería toda 
la composición, tal y como hace por ejemplo en su Sinfonía n. ${ }^{\circ} 4$.

Imagen 7. Primeros compases del segundo movimiento, "Allegro energico", de la Sinfonía Aitana.

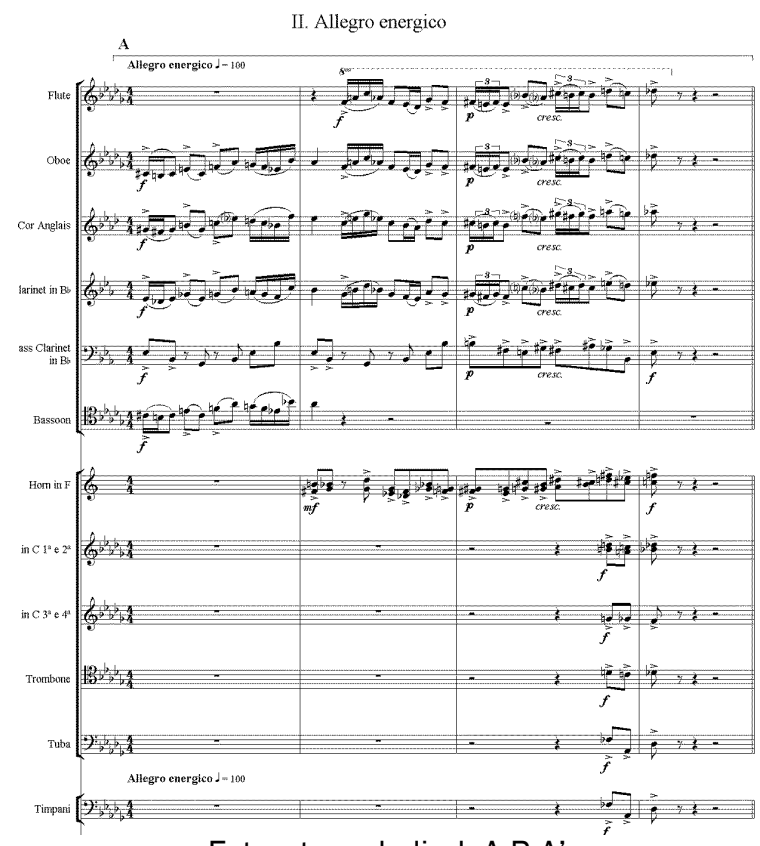

Estructura de lied: A B A'

Copyright de la imagen (c) Rosa Elia Castelló Gómara

No cabe duda de que la primera audición del segundo tiempo de la Sinfonía Aitana puso en evidencia la capacidad del público, de la crítica y de la orquesta. Para el primero exigió una concentración interior elevada, para lo cual en la mayoría de los casos no estaba ni está preparado. La crítica necesitaba tiempo con la esperanza de encontrar aquello que no le fue posible descubrir en la primera audición. La orquesta tuvo y tendrá cada vez que la interprete vencer las grandes dificulta-des de interpretación que encierra la partitura.

Algunos estudiosos como José Perís han considerado este segundo tiempo como el más importante de la sinfonía, llegando a decir que aquí podría comienza la sinfonía, considerando la "Invocación" como una amplia introducción. El profesor Peris expone además que este segundo tiempo está construido como una forma libre de sonata, pero aclara que esta libertad es producto de la forma cíclica predominante, no sólo en el Allegro sino en toda la sinfonía. En su opinión todo, absolutamente todo, nace y se desarrolla aquí después del material temático del comienzo.

\section{III. “Andante fugato"}

El primer aspecto destacable de este tercer movimiento de la Sinfonía Aitana es la instrumentación, puesto que está escrito exclusivamente para ser interpretado por los instrumentos de cuerda frotada (violines I y II), violas, violonchelos y contrabajos), cuerda punteada (dos arpas) y cuerda percutida (piano). En segundo lugar, su estructura, estamos ante una fuga perfecta, lo que se denomina una "fuga de escuela" con todas sus peculiaridades: exposición, divertimentos, reexposición y coda.

Imagen 8. Primeros compases del tercer movimiento, "Andante fugado" de la Sinfonía Aitana.

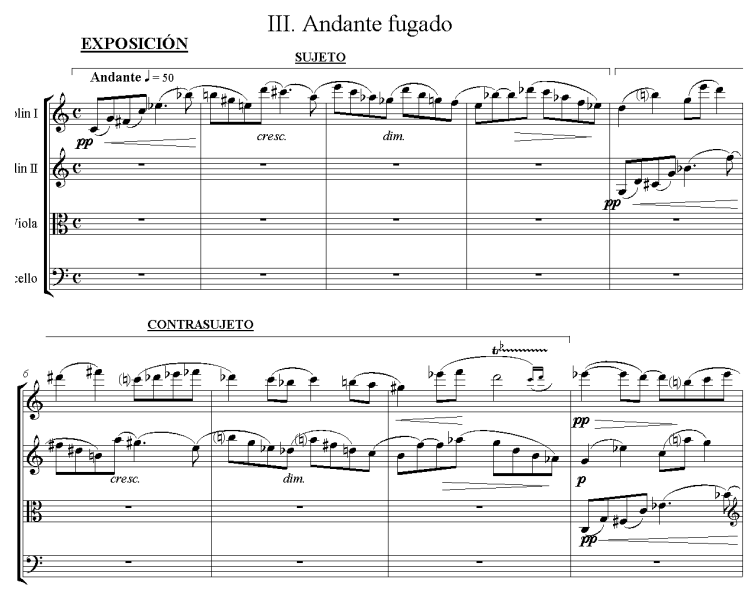

Copyright de la imagen (C) Rosa Elia Castelló Gómara

Este tercer movimiento parece estar compuesto bajo el influjo del poema sinfónico La Noche Transfigurada creado por Arnold Schönberg en el año 1899. La Noche 
Transfigurada podía considerarse un encuentro entre la solidez constructiva de Brahms y la tensión armónica y expresiva de Wagner; compuesto en un solo movimiento para sexteto de cuerda, en ella aparece una de las constantes de su producción, la textura contrapuntística, y aflora claramente la personalidad del compositor austríaco (Akal).

Imagen 9. Cuadro comparativo entre el tercer movimiento de la Sinfonía Aitana de Esplá y La noche transfigurada de Arnold Schöbnberg.

\begin{tabular}{|c|l|}
\hline $\begin{array}{c}\text { ÓSCAR ESPLÁ } \\
\text { "Andante fugato" } \\
\text { de la Sinfonía Aitana (1957) }\end{array}$ & ARNOLD SCHÖNBERG \\
\hline 6 grupos instrumentales & 6 instrumsfigurada (1899) \\
\hline Contrapunto & Contrapunto \\
\hline Austeridad de recursos & Austeridad de recursos \\
\hline Casi serial & Casi atonal \\
\hline Expresividad & Expresi vidad \\
\hline
\end{tabular}

Copyright de la imagen (c) Rosa Elia Castelló Gómara

Sorprendente es que el compositor alicantino haga uso, dada su postura estética, de estas técnicas cercanas a lo atonal y dodecafónico; la explicación es doble: primero un deseo de acallar las numerosas críticas que recibía por su aparente anclaje en el pasado y en segundo lugar, demostrar que conocía y dominaba todos los recursos de la vanguardia. Esplá podía haber compuesto mucho antes esta sinfonía con esos recursos seriales y no lo hace hasta que Schönberg, padre del atonalismo, muere (año 1951) tal y como hiciera también Igor Strawinsky6.

\footnotetext{
${ }^{6}$ El compositor ruso Igor Strawinsky, estéticamente opuesto a Arnol Schönberg, de acuerdo con sus ideas
}

$Y$ al igual que sucede en las sinfonías clásicas, finalizado el tercer tiempo, se attaca el cuarto, directamente, sin interrupción.

\section{IV. “Allegretto finale scherzando"}

La obra termina con un tempo rítmico claramente influenciado por el carácter de danza popular y por la polaridad armónica, mayor/menor que aquí es una obsesión desde el comienzo, como una exaltación que señala el triunfo sobre el planteamiento sereno de "Invocación" convertido a su vez en drama en el "Allegro". Confirmada queda, además, la importancia que el compositor concede a la subdominante dentro de un entramado armónico que no muestra un dominio que no desmerece su inspiración melódica.

Dividido en dos secciones similares $A$ (compás 1 a 96) - A' (compás 97 a 195), este movimiento, en ciertas partes recuerda a las estructuras de rondó (que se suelen emplear en los últimos movimientos de las sinfonías clásicas) en las que hay un tema recurrente y otros temas que se intercalan entre las exposiciones de ese tema reiterativo. Algo parecido es lo que hace aquí Esplá, la diferencia radica en que el compositor alicantino no llega a componer un verdadero tema, sino que expone un motivo rítmico-melódico que reaparece una y otra vez, variado y modificado; y sobre el que intercala otras ideas melódicas que en ningún caso llegan a ser verdaderos temas.

Imagen 10. Primeros compases del cuarto movimiento, "Allegreto finale scherzando" de la Sinfonía Aitana.

neoclásicas que pretendían recuperar las técnicas de épocas pasadas y darles una nueva lectura (la del siglo $\mathrm{XX}$ ), una vez muerto considera que ha muerto una época y por lo tanto es necesario realizar una nueva lectura de su música. Es en este momento cuando Strawinsky emplea el método dodecafónico (Morgan). 


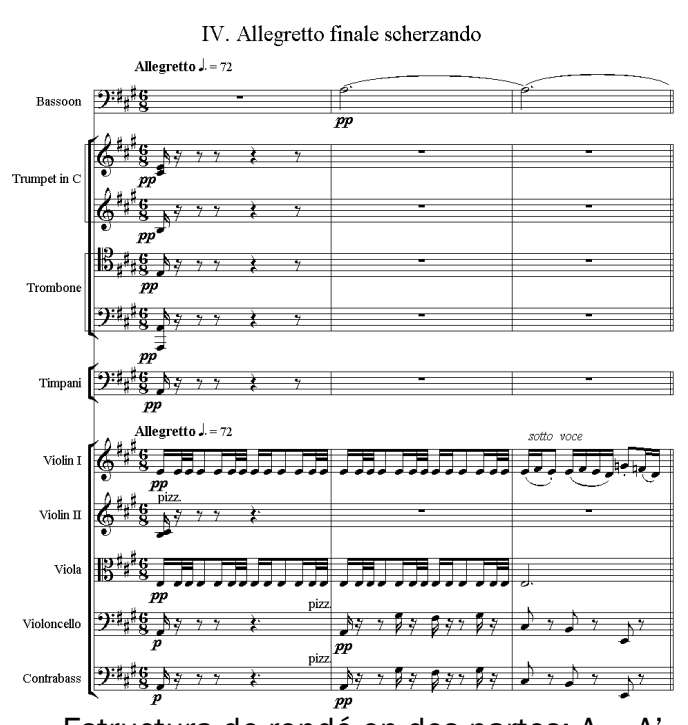

Estructura de rondó en dos partes: A - A'. Copyright de la imagen (c) Rosa Elia Castelló Gómara

La sinfonía concluye con una coda (compás 196 - 215) que puede dividirse en dos partes: Una primera donde el compositor recupera el tema principal (a) del primer tiempo "Invocación"; el tema interpretado por la flauta es similar al que toca el oboe en la primera presentación del tema: tenemos las mismas notas con pequeñas variaciones rítmicas. Y una segunda parte (los seis últimos compases) que son idénticos a la coda también del primer tiempo "Invocación", pero en otra tonalidad. Con esta coda cuyo material procede del primer tiempo ${ }^{7}$, Esplá concluye del mismo modo que comenzó con ese clima de ambigüedad y vaguedad que es el predominante en el panorama estético español del prácticamente todo el siglo XX.

\section{Conclusiones}

El estudio pormenorizado de la Sinfonía Aitana ha permitido extraer interesantes conclusiones: En primer lugar, Esplá domina a la perfección la instrumentación, contrariamente a lo que critica Tomás Marco, conoce

\footnotetext{
${ }^{7}$ La utilización de ideas que se presentan en el primer tiempo de la sinfonía y después se recuperan y desarrollan a lo largo de toda la partitura recuerda a la técnica compositiva denominada "forma cíclica", consistente precisamente en esto mismo que hace Esplá.
}

en profundidad la orquesta, sus instrumentos, sus posibilidades, por lo que se aprovecha de ello y juega con los timbres consiguiendo que un pequeño motivo adquiera diferentes matices sonoros; y para ello emplea la práctica totalidad de los instrumentos de la orquesta: violines I y II, violas, violonchelos y contrabajos; tres flautas y flautín; dos oboes y corno inglés; dos clarinetes y clarinete bajo; dos fagots $y$ contrafagot; cuatro trompas, tres trompetas, dos trombones y tuba; percusión, piano y dos arpas. En segundo lugar, observamos que Esplá no es un compositor de grandes temas que exponga y desarrolle; él se centra en pequeñas ideas, y es admirable la capacidad que posee para crear a partir de una pequeña célula todo un movimiento de sinfonía, transformándola hasta lo insospechado. La originalidad melódica que presenta la obra de Esplá escapa a toda clasificación posible. No menos sorprende la armonización de la partitura; una armonía novedosa y distinta que no llega a ser atonal totalmente, pero que explota al máximo las posibilidades tonales llegando a sus límites; por una parte demuestra que es posible hacer cosas originales sin necesidad de romper con el entramado tonal, y por otra que conoce suficientemente las técnicas compositivas atonales y dodecafónicas y hace uso de ellas con una soltura y un dominio tales que consiguió acallar las críticas que le tildaban de ignorante en la materia. Tampoco podemos olvidar el carácter evocador y descriptivo de muchos momentos de la sinfonía; rasgo que conecta claramente esta obra con la denominada música programática y con el folklore levantino, aunque en ningún momento podamos decir con exactitud qué es y dónde está ese elemento folklórico. Finalmente, decir que la Sinfonía Aitana parece ser una especie de "recopilación" de las grandes estructuras utilizadas a lo largo de la historia de la música planteadas desde una 
perspectiva cercana a la estética "neoclásica": la "casi" forma sonata del primer tiempo, la forma lied del segundo, la fuga del tercero y, por último, la forma binaria con elementos cercanos al rondó del cuarto movimiento. Además, tampoco podemos olvidar ese carácter cíclico que presenta la partitura en muchos momentos.

Es evidente que en la Aitana están presentes una vez más en Esplá, sus cualidades nacionales, o más bien regionales y levantinas, sin menoscabo de un europeísmo y una categoría universal. En esta obra confluyen la gran forma, la sensibilidad mediterránea en expresión estilizada de localismo y la orquestación magistral. El sinfonismo de Esplá es nuevo, basado en esencias nacionales incorporadas al momento contemporáneo de su arte evolucionada, en signo de positivo avance. El maestro alican-tino pone su sabiduría al servicio de sus ideaciones, resultando tanto más transcendente cuanto mayor y más alto es su propósito.

La Sinfonía Aitana es el paradigma perfecto de aquella frase que el filósofo Eugenio D`Ors dijo para referirse a Oscar Esplá: "la obra bien hecha". El autocrítico compositor alicantino jamás dejaba salir de su pluma camino de los atriles una partitura que no estuviese pensada, meditada, realizada, revisada y vuelta a revisar, es decir, perfecta. La Sinfonía Aitana fue madurada durante mucho tiempo en la mente y en la mesa del compositor alicantino (como prácticamente todo lo que compuso y escribió); constituye así una página de capital importancia de la música española del siglo $\mathrm{XX}$, por su rica escritura, por su espléndido talante y por la trabajada variedad temática, tímbrica, armónica, rítmica e instrumental.

Hay en Esplá, junto a ese cúmulo de exigencias formales, una veta lírica -que a veces parece volar hacia expresiones de cuño romanticista- y una como ruda ironía, que aunque evidente, difícil de traducir por los intérpretes. Ironía que en ocasiones es la aparición de un tema que caracteriza un estilo subrayándolo con ampulosidad, en otras sirve de pudor para esconder artísticamente la riada efectiva que suele desprenderse de la calidad humanística de su inspiración; otras, en fin, no es sino un juego con lo pequeño, infantil y vulgar logrado con los "primores" que Ortega señalaba para otro gran levantino: Azorín.

La Sinfonía Aitana de Oscar Esplá es una composición eminentemente levantina, plena de claridades, de rumores marinos $y$ huertanos, azulada, tierna y dura; resume toda la poesía tantas veces sentida de esa región española en la que el campo y el mar, flora y fauna, se hermanan y de cuya conjunción brotan la poesía de Gabriel Miró, los paisajes de Emilio Varela y el sinfonismo de Oscar Esplá.

La tradición clásica habla de écfrasis cuando un texto verbal describe precisa y detalladamente una obra de arte visual, real o ficticia. Si consideramos la Sierra de Aitana, sus manantiales, su flora, su fauna..., como esa obra de arte en la que se inspiran Gabriel Miró, Emilio Varela y Óscar Esplá, sus trabajos (literarios, pictóricos y musicales) podrían considerarse una écfrasis dado que son representaciones de ese objeto artístico, a través de las cuales ellos tratan de transmitir, esclarecer su sentir más profundo, con relación a Aitana. Aitana es la fuente de inspiración que desencadena el trabajo de esto artistas alicantinos; inspiración, pero no imitación, pues es imposible trasladar tal cual, a las cuartillas, los lienzos o los pentagramas Aitana, y que ese texto, cuadro o partitura, pueda ser considerado obra de arte. En definitiva, tres dimensiones artísticas de un mismo hecho estético.

Imagen 11. Sierra de Aitana y Pantano de Guadalest. 

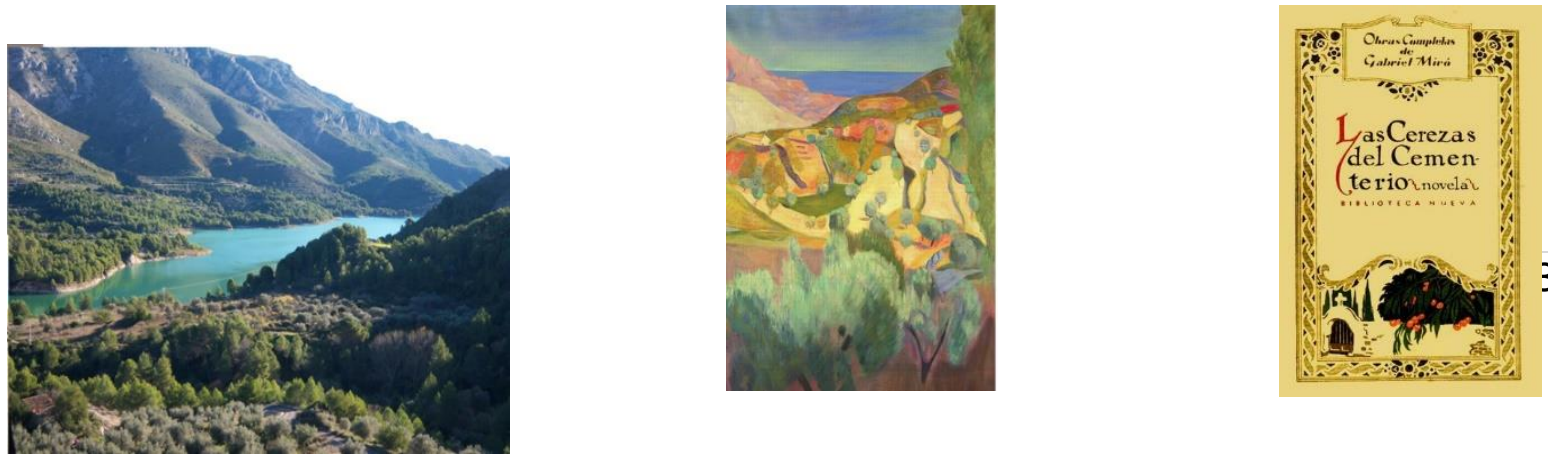

Écfrasis: Óscar Esplá (música)/ Emilio Varela (pintura)/ Gabriel Miró (Literatura).

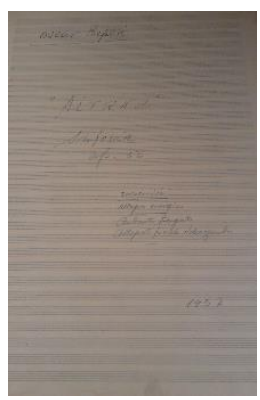




\section{BIBLIOGRAFÍA}

-BENEDETTO, R. (1987). El siglo XIX (Primera parte). Madrid: Turner Música.

-CASTELLÓ GÓMARA, R.E. (2013). La obra de Oscar Esplá: Música, literatura y pensamiento estético. Tesis doctoral dirigida por Pedro Aullón de Haro y JoséMaría Esteve-Faubel. Universidad de Alicante.
-LAMARTINE, A. (1981). Méditations poétiques, Marius-François Guyard (Éditeur scientifique). Paris: Gallimard.

-MORGAN, R. P. (1991). La música del siglo |74 $X X$. Madrid: Akal.

-PLANTINGA, L (1984). La música romántica. Madrid, Akal. 